\title{
National Ignition Facility SubSystem Design Requirements Beam Transport Enclosures SSDR 1.4.1
}

J. Meick

October 4, 1996

This is an informal report intended primarily for internal or limited external distribution. The opiniens and conclusions atated are those of the author and may or may not be those of the Laboratory.

Work performed under the aupices of the U.S. Department of Energy by the Lawrence Livermore National Laboratory under Contract W-7405-Eng-48. 


\section{DISCLAMMER}

This document was prepared as an account of work sponsored by an agency of the United States Government. Neither the United States Government nor the University of California nor any of thair employees, makes any warranty, express or implied, or asumes any lesal biability or respondibility for the accuracy, completeness, or weefulness of any information, epperntus, product, or process disclosed, or represents that its use would not infringe privately owned rights. Reference herein to any specific commercial product, procees, or service by trade name, trademark, manufacturex, or otherwise, does not necessarily constitute or imply its endorsement, recommendation, or favoring by the United States Covernment or the University of California. The views and opinions of authors expreseed herein do not necescarily state or reflect those of the United States Government or the University of Californin, and shall not be used for advertising or product endorsement purposes.

This report has been reproduced directly from the best available copy.

Available to DOE and DOE contractors from the Office of Scientific and Technical Information P.O. Box 62, Oak Ridge, TN 37831

Prices available from (615) 576-8101, FTS 626-8401

Avalable to the public from the

National Technical Information Service

U.S. Department of Commerce 5285 Port Royal Rd.

Springfield, VA 22161 


\section{National Ignition Facility}

\section{Subsystem Design Requirements}

Beam Transport Enclosures'

SSDR 1.4.1

\section{Revision B}

October 4, 1996

Prepared by:

J. Meick, Beam Transport Enclosures Lead Engineer $\frac{\text { Doseph Mewh }}{\text { Date }}$

Reviewed:

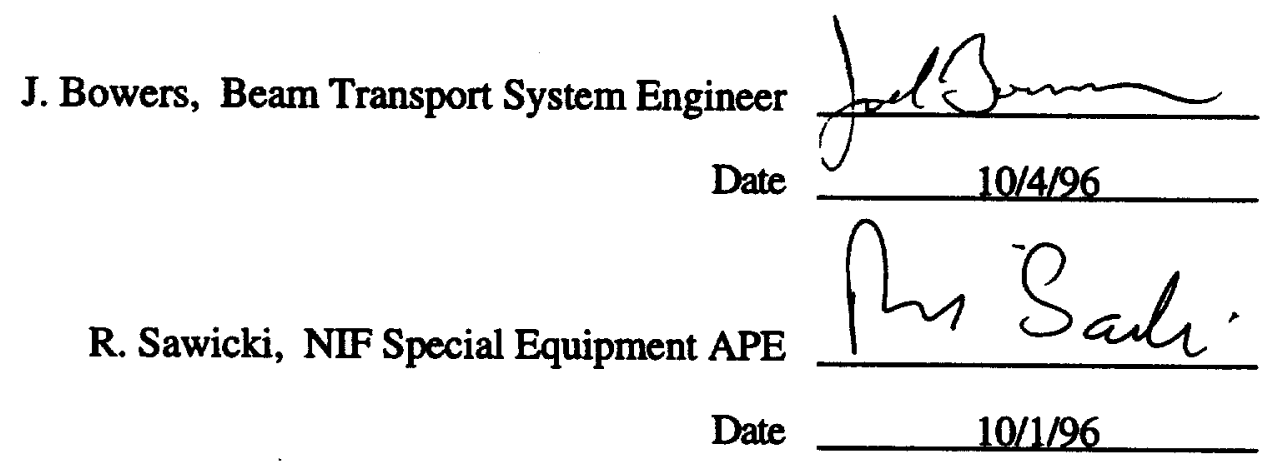

Level 4 Configuration Control Board Approval:

S. A. Kumpan, NIF Project Engineer

Date

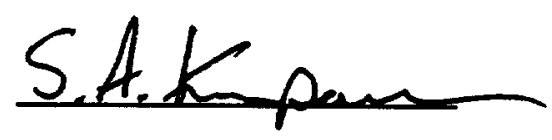

$10 / 4 / 96$ 


\section{Table of Contents}

\section{Paragraph}

1.0

2.0

2.1

2.1.1

2.1.2

2.1.3

2.2

2.2.1

2.2.2

2.3

2.4

3.0

3.1

3.1.1

3.1.2

3.1.3

3.1.3.1

3.1.4

3.1.4.1

3.1.4.2

3.1.4.3

3.1.4.4

3.1 .5

3.2

3.2.1

3.2.1.2

3.2.1.2.1

3.2.1.2.2

3.2.1.3

3.2.1.4

3.2.1.5

3.2 .2

3.2.2.1

3.2.2.2

3.2 .3

3.2.3.1

3.2.3.2

3.2.3.3

3.2.3.4

3.2.3.5

3.2.3.6

3.2 .4

3.2.4.1

3.2.4.2

\section{Title}

Scope

Applicable Documents

Applicable NIF Project Documents

Applicable NIF Project Documents

Applicable NIF Drawings

Interface Control Documents

Applicable US Government Orders, Codes, and Standards

DOE Orders

Other Government Regulations

Applicable National Consensus Codes and Standards

Applicable LLNL Standards

Subsystem Description and Characteristics

Subsystem Definition

Subsystem Description

Subsystem Functions

Subsystem Diagrams

Subsystem Operating Modes

Subsystem Interfaces

Transport Spatial Filter

Cavity Spatial Filter

Switchyard Beam Enclosures

Interstage Beam Enclosures

Major Components

Requirements and Verification

Performance Characteristics

Cleanliness

Internal Optical Cleanliness

General Cleanliness

Vibration Stability

Vacuum Level

Beam Enclosure Pressure

Physical Characteristics

Beam Transport Tube Size

Beam Tube Access

Reliability, Availability, Maintainability

Lifetime

Replaceability

Inherent Availability

Reliability

Maintainability

Recovery From abnormal events

Environmental

Ambient Temperature/Humidity

Ambient Cleanliness 


\section{Table of Contents}

\section{Paragraph}

3.3

3.3.1

3.3.2

3.3.2.1

3.3.2.2

3.3.2.3

3.3.4

3.3.5

3.3.6

3.3.7

3.3.8

3.3 .9

3.4

3.4 .2

3.4 .3

4.0

4.1

6.0
Title

Design and Construction

Natural Hazards Classification

Safety

Life Safety

Laser Safety

Occupational Safety

Future Modifications and Upgrades

Decommissioning

Human Factors

Interchangeability

Documentation and Records

Design Processes

Logistics

Maintenance Equipment

Bottom-Access Maintenance

QA Provisions

Q-level Assigned

Revision Record 


\subsection{Scope}

This SSDR establishes the performance, design, development, and test requirements for the NIF Beam Transport Enclosures (WBS 1.4.1

\subsection{Applicable Documents}

This section lists the NIF Project Documents, DOE and other government orders, codes, and standards, and national consensus standards which are applicable to the NIF Beam Transport Enclosures. Applicable LLNL standards are also being considered contingent upon the decision of final site selection.

\subsection{Applicable NIF Project Documents}

The following NIF Project Documents apply to the Beam Transport Subsystem as specifically referenced in later sections.

\subsubsection{Applicable NIF Project Documents}

National Ignition Facility Functional Requirements and Primary Criteria, Revision 1.4,

"Proposed Metrication Policy for NIF," memo from R. Sawicki, NIF-LLNL-96-038, L-21248-01, 21 January, 1996

NIF Grounding Plan, NIF-LLNL-94-211, L-17346-1.

NIF-LLNL-93-044/L-15958-1, National Ignition Facility Quality Assurance Program Plan, November 1993

\subsubsection{Applicable NIF Drawings}

The following NIF Project drawings apply as specified in sections 3.2 to 3.6. The specified revision applies.

AAA-96-104905-0A, Layout, Beam Transport Configuration

AAA-96-100596-0B, LTAB NIF Optics Main Laser Optic System, 7/19/96

Parsons Drawing No CFG-201, "LTAB, Floor Plan at Level -0"', 4/16/96

\subsubsection{Interface Control Documents}

Interface requirements between WBS level 1.4.1 and other subsystems are controlled through separate Interface

Control Documents (ICDs). The list below contains the ICD numbers and interfaces.

ICD\# 1.4. - 1.7. Spatial Filter Center Vessel Interfaces, Position and Stability Reqirements

ICD\# 1.4.1.3 - 1.2.2 1 Laser Bay/Switchyard Wall Penetrations

ICD\# 1.7.2.7 - 1.4.1.2 Roving Pick Mirror Assembly and Switchyard Enclosures

ICD\# 1.4.1.2 - 1.8.5.4 Switchyard/Target bay Beam Tube Interface

ICD\# 1.3.2 - 1.4.1.3 Boost and Main Amplifier Enclosure to Interstage Beam Tube Interface

ICD\# 1.4.1.1. - 1.1.1.3.2 Spatial Filter Center Vessel Diagnostic/Alignment Towers and Transport and Handling ICD\# 1.4.1.3 - 1.1.1.3.2. Transport and Handling and Interstage Enclosure Ports

\subsection{Applicable US Government Orders, Codes, and Standards}

\subsubsection{DOE Orders}

The following DOE orders are specifically referenced elsewhere in this document, and are applicable to the Beam Transport Subsystem.

- $\quad 5700.6 \mathrm{C}$ - Quality Assurance

- 420.1 - Facility Safety

- 440.1 - Worker Protection Management for DOE Federal and Contractor Employees

- 5400.1 General Environmental Protection Program

\subsubsection{Other Government Regulations}

The following Government Regulations are specifically referenced elsewhere in this document, and are applicable to the Beam Transport Subsystem. 
- MIL-STD 1246C - Product Cleanliness for Levels and Contamination Control Program

- FED-STD-209E - Airborne Particulate Cleanliness Classes in Cleanrooms and Clean Zones

\subsection{Applicable National Consensus Codes and Standards}

The following National Consensus Codes and Standards are specifically referenced elsewhere in this document, and are applicable to the beam transport subsystem.

- ASME Boiler and Pressure Code Section VII and VIII

- ANSUAWS A2.4, Symbols for Welding Brazing and Nondestructive Testing.

- DOE-STD-1020-94 Natural Phenomena Hazards Design and Evaluation Criteria for DOE Facilities

- ANSI/ASME B1.1 Standard for bolt threads

- ASTM A307 Standard Specification for Carbon Steel Bolts an Studs, 60,000 psi Tensile Strength

- ASTM A325 Standard Specification for High Strength Bolts for Structural Steel Joints

- ASTM A36 Standard Specification for Structural Steel

- ASTM A449 Standard Specification for Quenched and Tempered Steel Bolts and Studs

- ASTM A490 Standard Specification for Heat-Treated Steel Structural Bolts, $150 \mathrm{ksi}$ Minimum Tensile Strength

- ASTM A6 Chemical analysis for structural steel

- ASTM A751, F606 -testing methods for bolts and studs

- ASTM D 3951 (packaging of bolts and studs)

- ASTM F568, A563 Appurtenances for structural steel (nuts and bolts)

\subsection{Applicable LLNL Standards}

Pending final site selection, the following LLNL standards apply to the beam transport subsystem.

LLNL M-012 Rev 7, Feb. 1993, "Design Safety Standards -Mechanical Engineering"

LLNL M-010, March 1989, "Health and Safety Manual"

LLNL, M010, "Hazards Control Manual"

LLNL, M-256 "Mechanical Engineering Design Practice"

LLNL "Mechanical Engineering Policy Procedures Manual"

\subsection{Subsystem Description and Characteristics}

\subsection{Subsystem Definition}

The Beam Transport Enclosures are defined as the hardware that contain the laser beam from beam injection at the transport spatial filter to the Target Bay wall. The NIF Beam Transport Enclosures must contain the laser beam and all the associated optomechanical hardware in a clean, stable environment.

\subsubsection{Subsystem Description}

The NIF Beam Transport Enclosures are vessels and sheet metal enclosures which contain the laser beam as it propagates from the Pre-amplifier to the Target Bay. The hardware includes the cavity and transport spatial filters, the interstage enclosures and the switchyard beam tubes. The Cavity and Transport Spatial filter enclosures are operated under vacuum. The enclosures located between major laser components (Interstage enclosures) and the switchyard beam tubes are operated nominally at the ambient pressure of the building.

\subsubsection{Subsystem Functions}

The function of the beam tube enclosures is to:

- safely contain laser beam within an appropriately controlled environment

- provide access for optomechanical system maintenance and removal of optic assemblies

- provide ports for beam injection and diagnostics

- provide a sufficiently stable support for optics 


\subsubsection{Subsystem Diagrams}

\subsubsection{Subsystem Operating Modes}

(Figure 3.1.3.1 identifies the sequence of operating modes planned for the NIF facility. The laser system will also operate in all these modes, following the same scenario as the overall facility. The beam transport subsystem can be operated in the following modes.

Subsystem and Component Debug during Assembly

Subassemblies within the beam transport subsystem can be individually acceptance tested before system assembly.

\section{Commissioning and Acceptance Testing}

The minimum operating unit is one bundle.

\section{Normal Operation}

The minimum evacuated unit is a bundle. ( 8 beams). Bundles can be operated independently.

\section{Maintenance}

Beam transport maintenance can only occur in a Laser Bay that is in a safe state. During maintenance the beam transport will conform to NIF maintenance schedules.

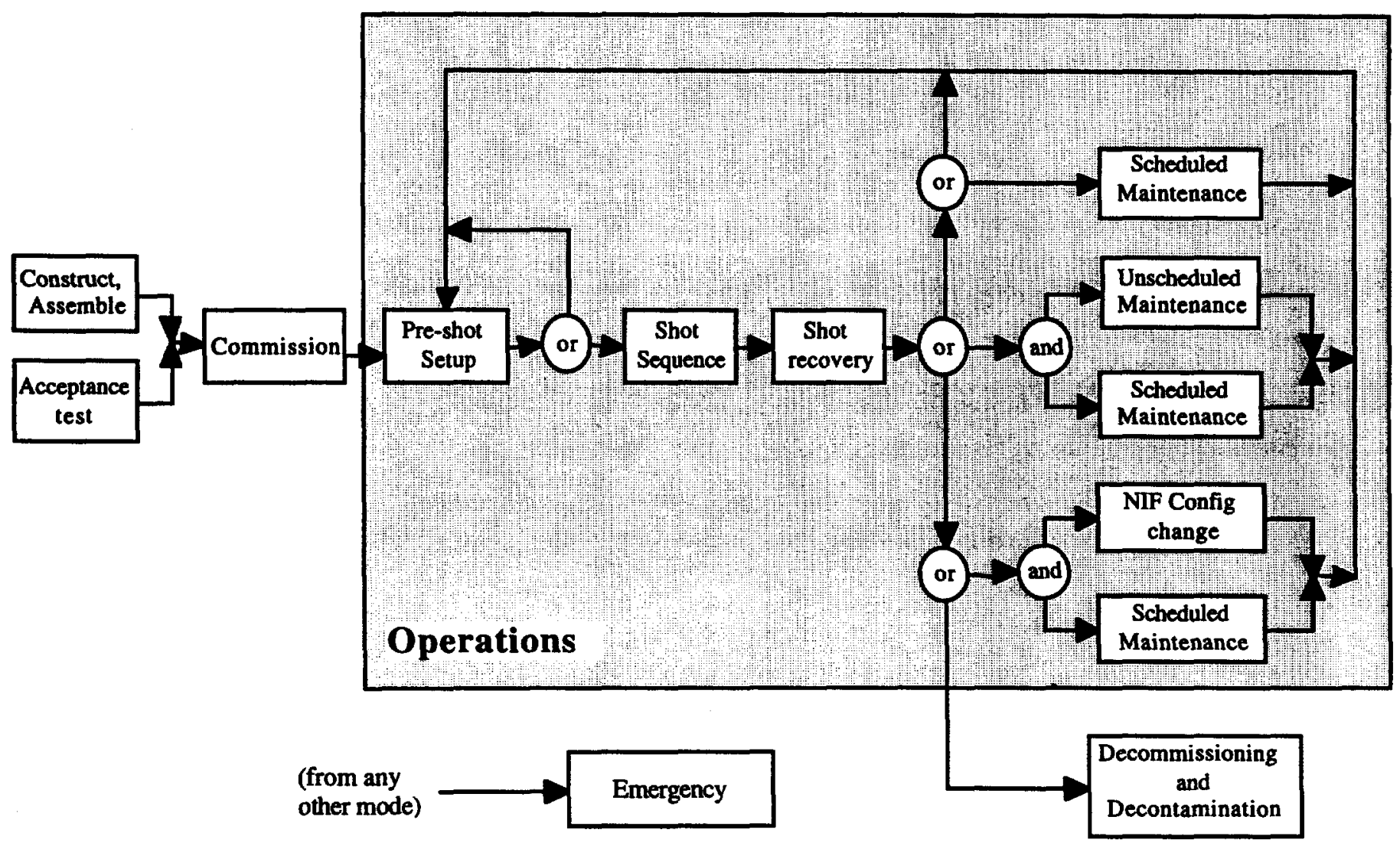

\subsubsection{Subsystem Interfaces}




\subsubsection{Transport Spatial Filter}

The Transport Spatial Filter (TSF) interfaces include:

Optical Pulse Generation System (WBS 1.3.1)

The laser beam is injected near the pin hole region of the Transport Spatial Filter through vacuum windows.

Laser Beam Diagnostics and Control (WBS 1.7)

Vacuum windows, located near the pin hole region of the Transport Spatial Filter, provide paths for diagnostic and alignment laser beams.

Optomechanical Systems (WBS 1.4.4.)

The TSF provides the interface that establishes the datum for proper location of the pinhole cassettes and end optic assemblies.

Laser Bay Support Structures (WBS 1.4.3.2)

A structure supports the TSF.

Transport and Handling (WBS 1.1.1.3.2)

Optics handling equipment docks with the TSF for removal of the optical assemblies at the pinhole area

Auxiliary Systems (WBS 1.4.2)

Vacuum piping and inert gas backfill systems are connected to the TSF with standard connections.

\subsubsection{Cavity Spatial Filter}

The Cavity Spatial Filter (CSF) interfaces include:

Laser Beam Diagnostics and Control (WBS 1.7)

Vacuum windows, located near the pin hole region of the Cavity Spatial Filter, provide paths for diagnostic and alignment laser beams.

Optomechanical Systems (WBS 1.4.4)

The CSF provides the interface that establishes the datum for proper location of the pinhole cassettes.

Laser Bay Support Structures (WBS 1.4.3.2)

A structure supports the CSF

Transport and Handling (WBS 1.1.1.3.2)

Optics handling equipment docks with the CSF for removal of the optical assemblies at the pinhole area and the full aperture optics at the ends of the CSF.

Auxillary Systems (WBS 1.4.2)

Vacuum piping and inert gas backfill systems are connected to the CSF with standard connections.

\subsubsection{Switchyard Beam Enclosures}

The Switchyard Beam Enclosures interfaces include:

Optomechanical Systems (WBS 1.4.4)

The switchyard beam enclosures interface with the turning mirror box enclosures. (LM4 and LMS)

Auxillary Systems (WBS 1.4.2)

The inert gas within the beam tubes is provided by Beam Transport Auxiliary systems.

Laser Beam Diagnostics and Control (WBS 1.7.2) 
The roving pick-off mirror and the roving calormeter are contained within an enclosure.

Switchyard Support Structures (WBS 1.4.3.1)

A structure supports the beam enclosures within the switchyard.

\subsubsection{Interstage Beam Enclosures}

Interstage Beam Enclosure interfaces include:

\section{Main and Boost Amplifiers (WBS 1.3.2)}

The Interstage Beam Enclosures contain the laser light as it enters and leaves the amplifiers.

Pockels Cell/Periscope Enclosure (WBS 1.4.3)

The Interstage Beam Enclosures contain the laser light as it enters and leaves the Pockels Cell/Periscope Enclosure.

Spatial Filters (WBS 1.4.1)

The Interstage Beam Enclosures contain the laser light at the ends of the spatial filters

Transport and Handling (WBS 1.1.1.3.2)

Transport and Handling systems remove the spatial filter end optic assemblies ( $1 \times 4$ column) through access ports located in the interstage beam enclosures.

\subsubsection{Major Components}

The major components of the beam transport subsystem are:

Transport Spatial Filters

Cavity Spatial Filters

Switchyard Beam Enclosures

Interstage Beam Enclosures

\subsection{Requirements and Verification}

\subsubsection{Performance Characteristics}

\subsubsection{Cleanliness}

\subsection{Internal Optical Cleanliness}

During operation of the laser, the optical elements within the beam transport enclosures shall be maintained at a surface cleanliness level as defined by MII-STD-1246C - Level 50. Permissible cleanliness degradation shall be budgeted across the assembly, measurement, transport, storage, installation and operation phases of laser construction. This budget is described in the document entitled, "Cleanliness Degradation Budgeting for the NIF Laser." The NVR (Non Volatile Residue) level for optical components shall conform to Level Aof MIL-STD$1246 \mathrm{C}$ or $1 \mathrm{mg} \mathrm{m}^{-2}$.

\subsection{General Cleanliness}

Wherever feasible, beam transport enclosure equipment to be deployed in the laser bays, switchyard, target bay, or other "clean" area shall be designed and constructed for class 10,000 clean room use, and shall be compatible with cleaning by aqueous solutions.

\subsubsection{Vibration Stability}

The beam enclosures in conjunction with associated structural elements shall provide vibrational stability such that the enclosed optomechanical equipment meet their tolerance requirements, while being exposed to ambient random vibration of $10^{-10} \mathrm{~g}^{2} / \mathrm{Hz}$, from 1 to $200 \mathrm{~Hz}$, applied at the special-equipment mounting surface of the foundation of the Laser or Target Area building. 


\subsubsection{Vacuum Level}

Spatial filter methods, fabrication techniques and material selection shall be consistent with $10^{-3}$ torr vacuum.

\subsubsection{Beam Enclosure Pressure}

All Beam Enclosures and Beam Tubes shall be designed to contain inert gas at a positive pressure of $500 \pm 250 \mathrm{~Pa}$.

\subsubsection{Physical Characteristics}

\subsubsection{Beam Transport Tube Size}

The beam transport enclosures shall be appropriately sized to safely contain the laser beams and all associated optomechanical hardware and allow transport to the facility using commercial carriers.

\subsubsection{Beam Tube Access}

The beam transport enclosures will be designed with access ports that are appropriately sized to meet the requirements of the optic assemblies.

\subsubsection{Reliability, Availability, Maintainability}

\subsubsection{Lifetime}

The beam transport enclosures shall operate for 30 years.

\subsubsection{Replaceability}

Any portion of the beam transport enclosures which cannot reasonably be designed for 30 year lifetime shall be designed to be replaced or repaired at reasonable cost in a timely manner consistent with the overall availability of the System.

\subsubsection{Inherent Availability}

The beam transport enclosures shall have a shot availability of at least $99.99 \%$. The system is unavailable when it is undergoing unplanned maintenance. Unplanned maintenance includes failure detection and active repair as well as logistic and administrative downtimes.

\subsubsection{Reliability}

The beam transport enclosures shall have an overall reliability of $99.999 \%$. Reliability is defined as the probability of meeting the minimum requirements of the experiment per no-yield shot as stated in SDR2:3.2.3.4.

\subsubsection{Maintainability}

The beam transport enclosures shall have a scheduled maintenance plan that fits within an overall annual plant goal of 69 days. The unplanned maintenance goal is 1 hour per year. Opportunistic maintenance activities are performed between shots and during other system downtimes.

\subsubsection{Recovery From abnormal events}

The time required for the beam transport enclosures to recover from any abnormal event shall be less than the maximum times cited below, as a function of the expected yearly frequency of occurrence of the event.

\begin{tabular}{cc} 
Expected Frequency of Occurrence Per Year. $F$ & Maximum Recovery Time \\
\hline$F \geq 1$ & 24 hours \\
$1>F>1 E-2$ & 1 week \\
$1 E-2>F \geq 5 E-4$ & 3 months
\end{tabular}

Probabilities listed in DOE-STD-1020-94 shall be used for natural phenomena

\subsubsection{Environmental}


The site for NIF has not yet been selected. The present design is therefore non-site-specific. For the purpose of Title I design, it shall be assumed that NIF will be constructed at a site with the general infrastructure as available at candidate sites. Specific environmental assumptions are listed in the following sections.

\subsubsection{Ambient Temperature/Humidity}

All beam transport enclosures subsystem components within the Laser Building shall meet all requirements when operated at a temperature of $20^{\circ} \mathrm{C} \pm 0.3^{\circ} \mathrm{C}$, a relative humidity of $30 \%$ to $60 \%$, and a pressure equal to ambient atmospheric pressure $\pm 10 \mathrm{~cm}$ water (to accommodate positive/negative air systems). Any components normally operated outside the LTAB Building shall meet all requirements when operated between $-4.4^{\circ} \mathrm{C}$ (dry bulb, winter) and $20.6^{\circ} \mathrm{C}$ (wet bulb, summer) or $37.8^{\circ} \mathrm{C}$ (dry bulb, summer), and local atmospheric pressure.

\subsubsection{Ambient Cleanliness}

The beam transport enclosures subsystem shall meet all requirements when operated within the NIF LTAB. The ambient cleanliness levels in pertinent areas of the LTAB are as follows:

$\begin{array}{lc}\text { Area } & \text { Ambient Cleanliness Class } \\ \text { Laser Bay } & 100,000 \\ \text { Switch yard } & 100,000 \\ \text { Target Bay } & 100,000\end{array}$

\subsection{Design and Construction}

The design and construction of the enclosures shall be consistent with applicable chapters of ASME Boiler and Pressure Code Section VIII and LLNL M-012 Rev 7, Feb 1993, "Design Safety Standards -Mechanical Engineering". Welding symbols shall conform to ANSUAWS A2.4, Symbols for Welding Brazing and Nondestructive Testing. Welding procedures and welder qualification shall be in accordance with Section IX "Welding and Brazing Qualifications,"of the ASME Boiler and Pressure Code. Base material and filler material shall conform to the appropriate section of the ASME Boiler and Pressure Code Section II "Materials Specifications," or acceptable AWS Standards.

\subsubsection{Natural Hazards Classification}

Beam enclosures shall meet the performance class 2 (PC2) design goals in DOE-1020.

\subsubsection{Safety}

Unless otherwise specified herein, all elements of the beam enclosures shall meet the requirements of the LLNL Mechanical Engineering Design Safety Standards, Electrical Engineering Design Standards, and Laser safety standards.

\subsubsection{Life Safety}

Life Safety shall comply with DOE Order 420.1 , Facility Safety. The beam enclosures shall not interfere with adequate means of egress, protection of vertical openings, travel distances, capacities, and emergency lighting.

\subsubsection{Laser Safety}

All beam enclosures within the laser bay shall comply with requirements of ANSI Z136.1 regarding laser safety..

\subsubsection{Occupational Safety}

Industrial hygiene and occupational safety shall comply with 29 CFR 1910 and DOE Order 440.1, Worker

Protection Management for DOE Federal and Contractor Employees.

Construction safety shall comply with the requirements of 29 CFR 1926, OSHA and DOE Order 440.1, Worker Protection Management for DOE Federal and Contractor Employees.

\subsubsection{Future Modifications and Upgrades}

As a design goal, the Laser System shall provide for future reconfiguration and modification at minimum cost and with minimum effect on the overall operation of the facility as per section 3.2.1.22.2 of SDR2. 


\subsubsection{Decommissioning}

The beam enclosures shall include considerations to allow cost effective future decommissioning of all structures and equipment.

\subsubsection{Human Factors}

The beam enclosures shall be designed in an ergonomic fashion to ensure that human reliability during operation and maintenance is sustained at a level consistent with meeting overall availability and reliability objectives. Consistency in human interfaces should be maintained.

\subsubsection{Interchangeability}

Interchangeability of components shall be preserved as much as practical. Equipment with the same function and physical characteristics shall be interchangeable.

\subsubsection{Documentation and Records}

The beam enclosures shall provide sufficient documentation to comply with the NIF Quality Assurance Plan, and DOE Order 5700.6C, Quality Assurance, Criterion-4 Documents and Records, which states: "Documents shall be prepared, reviewed, approved, issued, used and revised to proscribe processes, specify requirements or establish design. Records shall be specified, prepared, reviewed approved and maintained."

Examples of documents that should be controlled include drawings, data files, calculations, specifications, computer codes, purchase orders, vendor supplied documents, procedures, work records and data sheets and test records. Revisions should be reviewed by the organizations that originally prepared and approved the documents. Controlled documents should be distributed to those doing the work.

\subsubsection{Design Processes}

Design shall be carried out using sound engineering principles and appropriate standards. Design work including changes shall incorporate applicable requirements and design bases. Interfaces shall be identified and controlled. The adequacy of design products shall be verified or validated by qualified individuals other than those who did the work. Verification and Validation work shall be completed before approval and implementation of the design.

\subsection{Logistics}

Installation with the various beam transport enclosure assemblies shall be consistent with NIF Beam Transport System installation plan.

\subsubsection{Maintenance Equipment}

As a part of the design/construction project, the beam enclosure subsystem shall provide all equipment required to inspect, service, and maintain all subsystems within the Laser System to meet the maintainability and availability requirements in \$3.2.3. Maintenance equipment shall include all handling fixtures, lifting equipment, cleaning equipment and other special tools not otherwise available within NIF, that are necessary to perform any planned (scheduled or unscheduled) maintenance activity.

\subsubsection{Bottom-Access Maintenance}

As a design goal, all components within the beam enclosures in the laser bay should be accessible for maintenance from below, except for the spatial filter center vessels.

\subsection{QA Provisions}

Quality Assurance for this subsystem will be determined by verification methods identified in $\S 3$, in combination with the identified Quality Level for individual components.

\subsection{Q-Level Assigned}

\section{WBS}




\begin{tabular}{|c|c|c|c|c|c|}
\hline \multirow[t]{2}{*}{$\begin{array}{l}\text { element } \\
\text { number }\end{array}$} & \multirow[t]{2}{*}{ WBS element title } & \multicolumn{3}{|c|}{$\begin{array}{l}\text { Assigned } \\
\text { Q-level }\end{array}$} & \multirow[t]{2}{*}{ Why not Q-level 3 ? } \\
\hline & & 1 & 2 & 3 & \\
\hline 1.4.1.1 & Spatial Filter Vacuum Vessels & & $\sqrt{ }$ & & see $7 / 30$ draft \\
\hline 1.4 .1 .2 & Switchyard Beam Enclosures & & $\sqrt{ }$ & & see $8 / 2$ draft \\
\hline 1.4 .1 .3 & Laserbay Beam Enclosures & & T & & see $8 / 2$ draft \\
\hline
\end{tabular}

\subsection{Revision Record}

\begin{tabular}{|l|l|l|l|l|}
\hline Rev & Date & ECR\# & By & Description of/Reason for Change \\
\hline 0 & CDR & n/a & & \\
\hline A & $6 / 4 / 96$ & n/a & Meick & inital Title I issue \\
\hline B & $10 / 6 / 96$ & 60 & Meick & final Title I update, many miscellaneous changes, TBDs removed \\
\hline
\end{tabular}




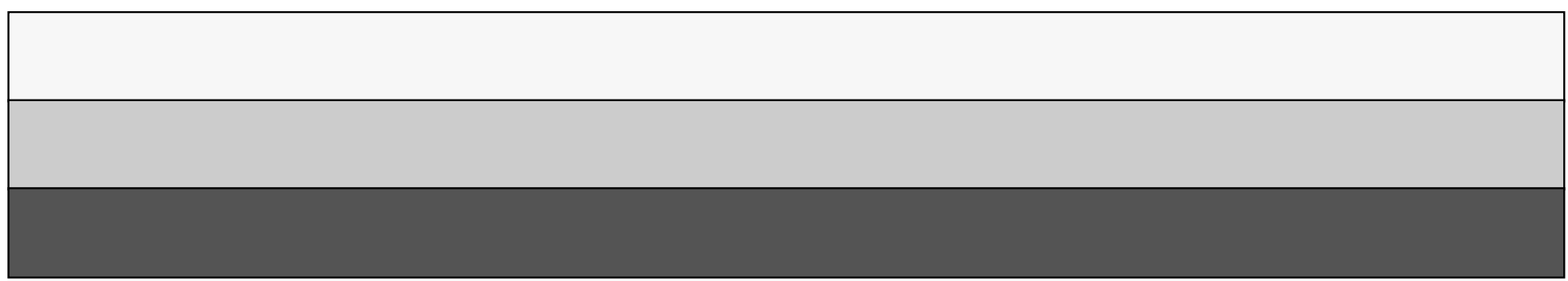

